\title{
AGRUPAMENTO DE CAFÉS CONILON ESPECIAIS POR CONDUTIVIDADE ELÉTRICA
}

\author{
Luina Ribeiro Noia' \\ Ana Beatriz Rocha de Jesus Passos ${ }^{2}$ \\ Jaqueline Rodrigues Cindra de Lima Souza ${ }^{3}$ \\ Adriano Azevedo Merçon 4 \\ Tércio da Silva de Souza ${ }^{5}$ \\ Marcia Flores da Silva Ferreira ${ }^{6}$ \\ Adésio Ferreira ${ }^{7}$
}

\begin{abstract}
Resumo: Métodos apropriados para a avaliação da qualidade sensorial do café conilon foram desenvolvidos recentemente e exigem provadores experientes e especializados. A análise da condutividade elétrica de exsudados dos grãos de café é um método auxiliar para determinação da qualidade do café, baseado no fato de a condutividade elétrica ser maior em grãos de café de menor qualidade por estes possuírem membranas menos íntegras, que lixiviam maior conteúdo de íons e solutos. Neste trabalho objetivou-se avaliar a capacidade de se discriminar cafés conilon especiais de cafés comerciais através da análise da condutividade elétrica dos grãos. Foram avaliadas 10 amostras de café conilon, cinco de cafés especiais e cinco de cafés comerciais. A análise de condutividade elétrica foi um método eficiente para discriminar os cafés especiais dos cafés comerciais, agrupando-os em dois grupos distintos pelo método UPGMA. Os valores de condutividade são maiores em cafés de menor qualidade, com grãos menores e maior percentagem de defeitos.
\end{abstract}

Palavras-chave: Coffea canephora, qualidade, análise sensorial, lixiviação de íons.

\footnotetext{
1 Agrônoma, Mestranda em Produção Vegetal/Universidade Federal do Espírito Santo/UFES, Brasil. E-mail: noia.luina@gmail.com.

${ }^{2}$ Química, Pós-doutoranda em Genética e Melhoramento/UFES, Brasil. E-mail: anabiapassos@yahoo.com.br.

${ }^{3}$ Química, Técnica de Laboratório/Instituto Federal do Espírito Santo/IFES, Brasil. E-mail: jrsouza@ifes.edu.br.

4 Técnico em Química, Técnico de Laboratório/IFES, Brasil. E-mail: adriano.azevedo@ifes.edu.br.

5 Químico, Professor/IFES, Brasil. E-mail: tssouza@ifes.edu.br.

${ }^{6}$ Bióloga, Professora/UFES, Brasil. E-mail: marcia.ferreira@ufes.br.

7 Agrônomo, Professor/UFES, Brasil. E-mail: adesioferreira@gmail.com.
} 